\title{
Heteronomie und Relativität in Schuldverhältnissen
}

\author{
Zur Haftung des Herstellers im europäischen Verbrauchsgüterkaufrecht
}

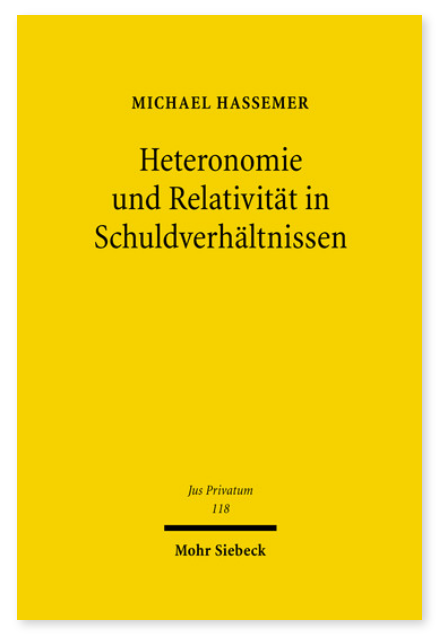

2007. XVII, 305 Seiten. JusPriv 118

ISBN 978-3-16-151195-0

DOI 10.1628/978-3-16-151195-0

eBook PDF 119,00€

ISBN 978-3-16-149143-6

Leinen $119,00 €$
In zahlreichen Ländern Europas haften Hersteller den Verbrauchern unmittelbar für Sachmängel. Die Europäische Kommission hat dieses Modell auch für die Richtlinie zum Verbrauchsgüterkauf angedacht, bislang allerdings nicht verwirklicht. Grund hierfür ist der Relativitätsgrundsatz: Verträge entfalten ihre Wirkungen grundsätzlich nur zwischen den Vertragsparteien. Obwohl das Relativitätsprinzip in allen europäischen Rechtsordnungen anerkannt ist, liegt sein genauer Gehalt bislang im Dunkeln: Im deutschen Recht geben der Vertrag zugunsten Dritter und der Vertrag mit Schutzwirkung für Dritte Beispiele. Michael Hassemer zeigt, dass das Relativitätsprinzip seinen Grund in der Selbstbestimmung des Einzelnen hat: Vertragsparteien können nicht autonom Rechtswirkungen gegenüber Dritten erzeugen, die, ebenso wie sie, selbstbestimmt sind. Die Relativität der Schuldverhältnisse verbietet somit die 'Fremdbestimmung unter Gleichen'. Wenn der Relativitätsgrundsatz seine Wurzel im Autonomieprinzip hat, so muss dies im Umkehrschluss bedeuten, dass heteronomes Schuldrecht als nicht von den Parteien, sondern vom Gesetzgeber oder Richter hergestelltes Recht dem Relativitätsprinzip nicht unterliegt: Eine 'Fremdbestimmung unter Gleichen' liegt im Falle heteronomen Schuldrechts nicht vor. Das europäische Verbrauchsgüterkaufrecht ist 'positiv zwingendes Recht' und damit über weite Strecken heteronomer Natur. Hieraus entwickelt der Autor ein Modell der Herstellerhaftung für Europa. Zugleich zeigt er die heute wesentliche Aufgabe des Privatrechts in der europäischen Rechtsentwicklung: Sein Instrumentarium muss sich dem heteronomen Zugriff auf das Vertragsrecht stellen.

Michael Hassemer Geboren 1966; Studium der Rechtswissenschaften in München; 1999 Promotion; 2006 Habilitation.

Jetzt bestellen:

https://mohrsiebeck.com/buch/heteronomie-und-relativitaet-in-schuldverhaeltnissen-9783161511950?no_cache=1 order@mohrsiebeck.com

Telefon: +49 (0)7071-923-17

Telefax: +49 (0)7071-51104 